\title{
Viscosity and Density of 1-Alkanol (C3-C11) Quaternary and Quinary Systems at Different Temperature Levels.
}

\author{
Nidal Hussein ${ }^{1 *}$, Abdul-Fattah Asfour ${ }^{2}$ Orabi Al Rawi ${ }^{3}$ \\ 1 Department of Civil Engineering, University of Petra, Amman-Jordan \\ 2 Department of Environmental Engineering, University of Windsor, Windsor, Ontario, Canada \\ 3 Department of Civil Engineering, Isra University, Amman, Jordan
}

\begin{abstract}
The measured kinematic viscosity and density and the calculated absolute viscosity for selected quaternary and quinary n-alkanol mixtures are presented in this study. The mixtures are composed of 1-propanol, 1-pentanol, 1heptanol, 1-nonanol, and 1-undecanol. Both the kinematic viscosity and density were measured for the pure components and several intermediate compositions for the selected mixtures at two temperature levels of 293.15 and $298.15 \mathrm{~K}$. The measured data were used to test the predictive capability of different models. The McAllister three body interaction model and the GC-UNIMOD model showed the best overall predictive capability of all models.
\end{abstract}

Keywords: Viscosity, Density, 1-Alkanol,Ternary systems, McAllister model

\section{INTRODUCTION}

Engineers in common with other scientists encounter different problems that require the knowledge of the transport properties of multi-component liquid mixtures. The literature contains a huge amount of data on the kinematic viscosity of liquid mixtures. Most of the data points are for binary mixtures. Although, the availability of these data are of a great importance, the need for a model that can represent the data and being able to predict the viscosity for other mixture without the need to conduct a costly and time consuming experiments is very important. In addition, it is assumed that the knowledge of the dependence of viscosity on temperature and composition leads to a better understanding of liquids' structure. Several researchers have developed models to predict the viscosity of liquid mixtures at different temperatures and composition based on the knowledge of some molecular parameters and/or properties of the pure components constituting the mixture. This resulted in the development of various viscosity models. Among the available models in the literature, four models were selected and tested. The selected models are: the generalized McAllister three-body interaction model (model 1) reported by Nhaesi and Asfour (2000), the GC-UNIMOD model (model 2) reported by Cao et al. (1993), the Generalized Corresponding States Principle (GCSP) model (model 3) reported by Teja and Rice (1981), and the Allan and Teja correlation (model 4) reported by Allan and Teja (1991). The objective of this work is to obtain and report the kinematic viscosities and densities of five quaternary and the quinary systems of (1-propanol, 1-pentanol, 1-heptanol, 1-nonanol, and 1-undecanol) over the entire composition range and at two different temperature levels of 293.15 and $298.15 \mathrm{~K}$. These data are required for their own value. Moreover, to use the reported data for testing the predictive capability of the selected viscosity models.

\section{Materials and Methods}

The chemicals used during the different stages of this study were supplied by Sigma-Aldrich and by Fluka. The stated purities of those chemicals were $99.0+\%$. A Hewlett-Packard 5890A Gas Chromatograph with a flame ionization detector (FID) and an HP 1 [cross linked methyl silicone gum] $30 \mathrm{~m}$ (long) $\times 0.53 \mathrm{~mm}$ (diameter) and $2.65 \mu \mathrm{m}$ (film thickness) column was used to verify the stated purity of those chemicals. The GC analysis confirmed that the purities of the chemicals were better than the stated values. The suppliers' stated purities and the GC analysis results of the chemicals used in the present study are reported in Table 1.

\subsection{Preparation of Solution}

All mixtures were prepared on a mass basis by weighing the pure components composing the mixture sample separately using a Mettler HK 160 electronic balance with a stated precision of $\left( \pm 1 \times 10^{-7} \mathrm{~kg}\right)$. The procedures described by Asfour (1979) were followed where the pure components were injected into glass vials sealed with Tuf-Bond discs and aluminum seals to prevent and change in the composition due to evaporation and moisture absorption. 


\subsection{Density Measurements}

The density measurements of the pure component and mixtures' samples were carried out by injecting samples into an Anton-Paar density meter that consists of a DMA 602 measuring cell and a DMA 60 processing unit. The stated uncertainty in the density meter measurements was estimated to be $\pm 1.5 \times 10^{-6} \mathrm{~kg} / \mathrm{L}$. The processing unit of the density meter reads the oscillation period that is converted to density using the following equation that is suggested by the instrument supplier:

$\rho=\frac{A T^{2}}{1-B T^{2}}-C$

in equation (1), $\rho$ is the calculated density in $\mathrm{kg} / \mathrm{L} . \mathrm{A}, \mathrm{B}$, and $\mathrm{C}$ are calibration constants that depend on the temperature and $\mathrm{T}$ is the oscillation period in seconds. The values of the calibration constants were determined by using the density values of octane, toluene, ethylbenzene, tridecane, and undecane, which were fitted using the least-squares technique to equation (1). Table 2 summerizes the values of the calibration constants used in density measurements.

The temperature of the measuring cell was kept within \pm $0.01 \mathrm{~K}$ of the desired level with the help of a Haake N4 circulator. The circulator water temperature was monitored by an Omega electronic thermometer fitted with a calibrated platinum temperature sensor (ITS-90) with a precision of $\pm 0.005 \mathrm{~K}$. To avoid the effect of the surrounding temperature fluctuation, the density meter was kept inside a wooden chamber described in details earlier by Asfour (1980) where the temperature inside is kept within $\pm 0.5 \mathrm{~K}$ of the desired temperature.

\subsection{Viscosity Measurements}

For the pure components and the selected samples, two sizes of the Cannon Ubbelohde glass viscometers were employed. The two sizes are: 100 and 150. Those viscometers are used to measure the kinematic viscosities that range between 3-15 and $7-35 \times 10^{-6} \mathrm{~m}^{2} / \mathrm{s}$, respectively. In order to calculate the viscosities of the samples to be studied, the efflux time was measured three times with electronic stopwatches with a stated accuracy of $\pm 0.01 \mathrm{~s}$ and the average value was substituted into the equation suggested by the viscometer manufacturer that has the following formula:

$v=C t-\frac{E}{t^{2}}$

where $v$ is the kinematic viscosity of the sample in $\mathrm{m}^{2} / \mathrm{s}$. $C$, and $E$ are the calibration constants and $\mathrm{t}$ is the efflux time in seconds. The calibration constants depend on the temperature and were determined by using calibration fluids of known viscosities supplied by Cannon Instrument Company. The calibration fluids used in this study are: S3, S6, and N10 with kinematic

Table 2 Calculated Values of Density Meter's Calibration Constants

\begin{tabular}{llll}
\hline \multicolumn{4}{l}{ Fitting Parameters } \\
\hline Temperature (K) & A & B & C \\
293.15 & 3.143115 & 0.1603187 & 0.9829897 \\
298.15 & 3.459062 & 0.07160815 & 1.066801 \\
\hline
\end{tabular}
viscosities that range between $4.62-22.7 \times 10^{-6} \mathrm{~m}^{2} / \mathrm{s}$. The viscosities of the calibration fluids and their corresponding efflux times were fitted using the least-squares technique to estimate the values of the calibration constants. The viscometers were placed in a Cannon CT-1000, constant temperature water bath where temperature can be controlled within $\pm 0.01 \mathrm{~K}$. The bath's water temperature was monitored by an Omega electronic thermometer described in the previous section. The measured kinematic viscosity was multiplied by the measured density value to obtain the absolute viscosity value of the sample.

\subsection{Model Description}

Among the available viscosity models in the literature, four widely used models were selected and tested. The selected models are: the generalized McAllister three-body interaction model (model 1) reported by Nhaesi and Asfour (2000), the GC-UNIMOD model (model 2) reported by Cao et al. (1993), the Generalized Corresponding States Principle (GCSP) model (model 3) reported by Teja and Rice (1981), and the Allan and Teja correlation (model 4) reported by Allan and Teja (1991). 
The generalized McAllister three-body interaction model for multi-component n-alkane and for regular solutions was developed and reported by Nhaesi and Asfour (2000). They suggested equation (3) for calculating the kinematic viscosity of any multi-component liquid system:

$$
\begin{aligned}
\ell \mathrm{nv}_{\mathrm{m}} & =\sum_{i=1}^{\mathrm{n}} x_{i}^{3} \ell \mathrm{n}\left(\mathrm{v}_{\mathrm{i}} M_{I}\right)+3 \sum_{i=1}^{n} \sum_{j=1}^{\mathrm{n}} x_{i}^{2} x_{j} \ell \mathrm{n}\left(\mathrm{v}_{\mathrm{ij}} M_{i j}\right) \\
& +6 \sum_{\mathrm{i}=1}^{n} \sum_{\substack{\mathrm{j}=1 \\
i \neq j \neq k}}^{n} \sum_{k=1}^{\mathrm{n}} x_{i} x_{j} x_{k} \ell \mathrm{n}\left(\mathrm{v}_{\mathrm{ijk}} M_{i j k}\right)-\ell \mathrm{n} \mathrm{M}_{\mathrm{m}}
\end{aligned}
$$

Where $\mathrm{M}_{\mathrm{ij}}$ and $\mathrm{M}_{\mathrm{ijk}}$ are the average molecular weight for binary and ternary interaction. For n-alkane mixtures, the binary interaction parameters $\left(v_{\mathrm{ij}}\right)$ and the ternary interaction parameters $\left(v_{\mathrm{ijk}}\right)$ in equation (3) are calculated using the equations (4) and (5) respectively:

$$
\begin{aligned}
& \frac{v_{i j}}{\left(v_{i}^{2} v_{j}\right)^{1 / 3}}=1+0.044 \frac{\left(N_{j}-N_{i}\right)^{2}}{\left(N_{i}^{2} N_{j}\right)^{1 / 3}} \\
& \frac{v_{i j k}}{\left(v_{i} v_{j} v_{k}\right)^{1 / 3}}=0.9941+0.03167 \frac{\left(N_{k}-N_{i}\right)^{2}}{N_{j}}
\end{aligned}
$$

Where $N_{\mathrm{i}}$ and $N_{\mathrm{j}}$ are the number of carbon atoms per molecule of components i and j respectively. As suggested earlier by Shan (2000) and Hussein (2007), the generalized version of the predictive model for multi-component n-alkane mixtures were used for the prediction of the viscosities of the 1-alkanol multi-component mixtures. The second model tested in this study is GC-UNIMOD reported by Cao et al.(1993). The viscosity equation in this model has the following formula:

$$
\ell \mathrm{n}(\mathrm{v})=\sum_{i=1}^{\mathrm{n}}\left[\phi_{i} \ell \mathrm{n}\left(\mathrm{v}_{\mathrm{i}} \frac{M_{i}}{M}\right)+2 \phi_{i} \ell \mathrm{n}\left(\frac{x_{i}}{\phi_{i}}\right)+\sum_{\text {allgroupsk }} \mathrm{v}_{\mathrm{k}}^{(\mathrm{i})}\left[\theta_{k i}-\theta_{k i}^{(i)}\right]\right]
$$

Where $\phi_{\mathrm{i}}$ is the average segment fraction of component $\mathrm{i}, \theta_{\mathrm{ki}}^{(\mathrm{i})}$ is the residual viscosity of group k for component $\mathrm{i}$ in a mixture-ofgroup of pure liquid i. $v_{\mathrm{k}}^{(\mathrm{i})}$ is the number of groups $\mathrm{k}$ per molecule of component $\mathrm{i}$. The generalized corresponding states principle (GCSP) model was reported by Teja and Rice (1981) and suggested equation (7)

$$
\ln (\mu \xi)=\ln (\mu \xi)^{r 1}+\frac{\omega-\omega^{r 1}}{\omega^{r 2}-\omega^{r 1}}\left[\ln (\mu \xi)^{r 2}-\ln (\mu \xi)^{r 1}\right]
$$

where $\mathrm{r} 1$ and $\mathrm{r} 2$ refer to the two fluids, $\mu$ is the absolute viscosity, $\omega$ is the acentric factor of the non-spherical fluid and $\xi$ is a constant calculated from the critical properties $\left(\mathrm{P}_{\mathrm{c}}\right.$ and $\left.\mathrm{T}_{\mathrm{c}}\right)$ of the fluid and is given by equation (8):

$\xi=P_{c}^{-2 / 3} T_{c}^{1 / 6} M^{-1 / 2}$

the critical pressure and temperature data were taken from Reid et al. (1987). The mixing rules described in details earlier by Wong et al. (1994) were also used when using the GCSP equation. The last model tested in this study is the correlative Antoine-type equation (9) proposed by Allan and Teja (1991) for the estimation of the absolute viscosity:

$$
\ln \mu=A\left[-\frac{1}{B}+\frac{1}{T+C}\right]
$$

where $\mathrm{A}, \mathrm{B}$, and $\mathrm{C}$ are constants that are correlated to the carbon numbers in the hydrocarbons composing the mixture. For $\mathrm{n}$ alkanes, $\mathrm{N}$ is the number of carbon atoms per molecule of the component. For non $\mathrm{n}$-alkane hydrocarbons, viscosity data measured experimentally are needed for the estimation of the effective carbon number.

\section{Results and Discussion}

The measured experimental values of density, kinematic viscosity, and the calculated absolute viscosity, $\mu$, of the pure components at 293.15 and $298.15 \mathrm{~K}$ and the corresponding literature values are listed in Table 3. Table 3 shows that the reported experimental values for density and kinematic viscosity and the corresponding literature values are in good agreement. The experimental values of 
the densities, kinematic viscosities, and the calculated absolute viscosities of the investigated quaternary and quinary systems are reported in Tables $\mathbf{4}$ and $\mathbf{5}$.

Table 3 Pure Components Properties and their Comparison with their Corresponding Literature Values at Different Temperatures

\begin{tabular}{|c|c|c|c|c|c|}
\hline & $\begin{array}{c}\text { This work } \\
\rho / \mathrm{kLL}^{-1}\end{array}$ & $\begin{array}{l}\text { Literature } \\
\rho / \mathrm{kgL}^{-1}\end{array}$ & $\begin{array}{l}\text { This work } \\
10^{6} \mathrm{v} / \mathrm{m}^{2} \mathrm{~s}^{-}\end{array}$ & This work & Literature \\
\hline Compound & & $\mathrm{T}=293.15 \mathrm{~K}$ & & Absolute Viscosity, mPa.s & \\
\hline 1-Propanol & 0.8035 & $0.8036^{1}$ & 2.828 & 2.272 & $2.196^{2}$ \\
\hline 1-Pentanol & 0.8146 & $0.8151^{2}$ & 4.946 & 4.029 & $4.0608^{2}$ \\
\hline 1-Heptanol & 0.8222 & $0.8225^{2}$ & 8.64 & 7.104 & $7.058^{3}$ \\
\hline 1-Nonanol & 0.8278 & $0.828^{2}$ & 1.411 & 11.683 & $11.635^{4}$ \\
\hline 1-Undecanol & 0.8324 & $0.8335^{2}$ & 2.064 & 17.182 & $17.284^{4}$ \\
\hline
\end{tabular}

Table 4 Density, Kinematic Viscosity, and Calculated Absolute Viscosity of Five Quaternary Subsystems of the Quinary System: 1-Propanol, 1Pentanol, 1-Heptanol, 1-Nonanol, and 1-Undecanol

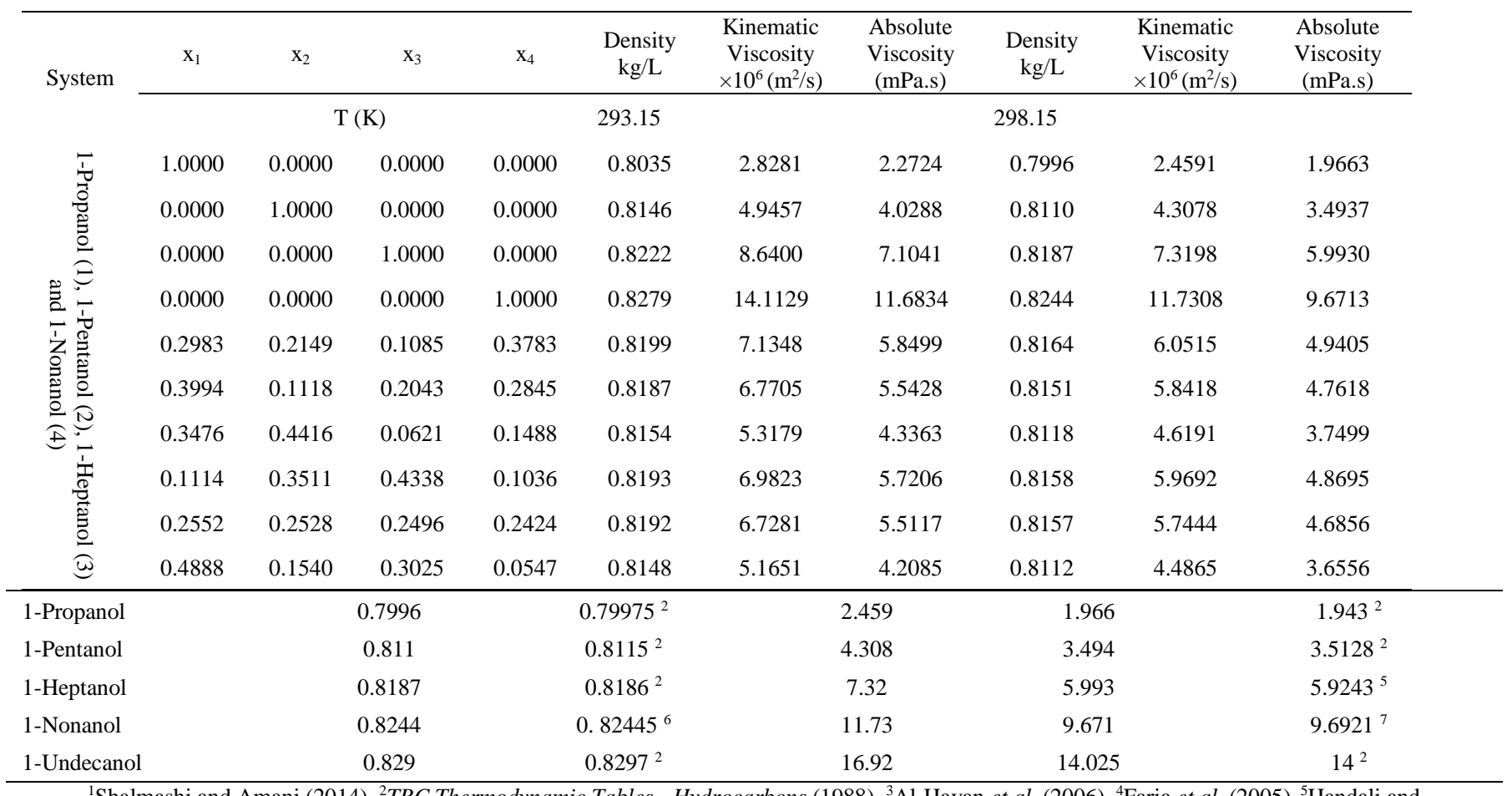

${ }^{1}$ Shalmashi and Amani (2014), ${ }^{2}$ TRC Thermodynamic Tables - Hydrocarbons (1988), ${ }^{3} \mathrm{Al}$-Hayan et al. $(2006),{ }^{4} \mathrm{Faria}$ et al. $(2005),{ }^{5} \mathrm{Handali}$ and Kianersi (2016), ${ }^{6}$ Gowrisankar et al. (2013), ${ }^{7}$ Al-Jimaz et al. (2004).

The measured kinematic viscosity values reported in Table 3, 4 and 5 are in agreement with the well established fact, that viscosity of liquids decreases with increasing temperature, this is applicable for pure liquids as well as liquid mixtures. The measured kinematic viscosity values reported in Table 4 and 5 were used to test the predictive capabilities of the previously mentioned models. The kinematic viscosity values calculated by these models were compared with the experimental values in terms of $\%$ average absolute deviation ( $\%$ AAD), and the maximum percentage deviation of the model from experimental data (\% MAX). The $\%$ AAD is calculated with the help of equation (10):

$\% A D D=\frac{1}{n} \sum_{i=1}^{n}\left(\frac{v_{i}^{\text {measured }}-v_{i}^{\text {predicted }}}{v_{i}^{\text {measured }}}\right) \times 100$

The $\%$ MAX is given by equation (11):

$\% \operatorname{MAX}=\operatorname{MAX}\left(\frac{v_{i}^{\text {measured }}-v_{i}^{\text {predicted }}}{v_{i}^{\text {measured }}}\right) \times 100$ 
where $\mathrm{n}$ is the number of the experimental points and $v$ is the kinematic viscosity. Tables $\mathbf{6}$ and $\mathbf{7}$ shows the results of testing the different models. The four models that were tested in the present study showed a variation in their predictive capabilities. The data reported in Table 6 and 7 show that the Generalized McAllister model gave the best overall predictive capability of all the tested models for quaternary system with an overall percentage average absolute deviation values was $1.093 \%$. Whereas, the GCUNIMOD model gave the best overall predictive capability of all the tested models for qirnary system with an overall percentage average absolute deviation values was $1.43 \%$. The two models, Generalized McAllister model and the GC-UNIMOD model, that gave the best predictions of kinematic viscosity of the investigated mixture are those based on theoretical basis that accounts for the different types of interaction that exist in liquid mixtures. Moreover, these two models takes into consideration the molecular structure of pure liquids that compose the mixture and the different types of the existing functional groups.

Table 4 continued

\begin{tabular}{|c|c|c|c|c|c|c|c|c|c|c|}
\hline System & $\mathrm{x}_{1}$ & $\mathrm{x}_{2}$ & $\mathrm{x}_{3}$ & $\mathrm{x}_{4}$ & $\begin{array}{c}\text { Density } \\
\mathrm{kg} / \mathrm{L}\end{array}$ & $\begin{array}{c}\text { Kinematic } \\
\text { Viscosity } \\
\times 10^{6} \\
\left(\mathrm{~m}^{2} / \mathrm{s}\right)\end{array}$ & $\begin{array}{c}\text { Absolute } \\
\text { Viscosity } \\
\text { (mPa.s) }\end{array}$ & $\begin{array}{c}\text { Density } \\
\mathrm{kg} / \mathrm{L}\end{array}$ & $\begin{array}{c}\text { Kinematic } \\
\text { Viscosity } \\
\times 10^{6} \\
\left(\mathrm{~m}^{2} / \mathrm{s}\right)\end{array}$ & $\begin{array}{c}\text { Absolute } \\
\text { Viscosity } \\
\text { (mPa.s) }\end{array}$ \\
\hline & \multicolumn{4}{|c|}{$\mathrm{T}(\mathrm{K})$} & \multicolumn{3}{|c|}{293.15} & \multicolumn{3}{|c|}{298.15} \\
\hline I & 1.0000 & 0.0000 & 0.0000 & 0.0000 & 0.8146 & 4.9457 & 4.0288 & 0.8110 & 4.3078 & 3.4937 \\
\hline 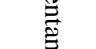 & 0.0000 & 1.0000 & 0.0000 & 0.0000 & 0.8222 & 8.6400 & 7.1041 & 0.8187 & 7.3198 & 5.9930 \\
\hline Е & 0.0000 & 0.0000 & 1.0000 & 0.0000 & 0.8279 & 14.1129 & 11.6834 & 0.8244 & 11.7308 & 9.6713 \\
\hline 产 & 0.0000 & 0.0000 & 0.0000 & 1.0000 & 0.8325 & 20.6395 & 17.1818 & 0.8290 & 16.9172 & 14.0250 \\
\hline 苍 & 0.2912 & 0.2342 & 0.1084 & 0.3662 & 0.8255 & 11.8776 & 9.8047 & 0.8221 & 9.9297 & 8.1628 \\
\hline 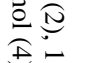 & 0.3967 & 0.1085 & 0.2032 & 0.2915 & 0.8247 & 10.9738 & 9.0501 & 0.8213 & 9.2062 & 7.5606 \\
\hline 文 & 0.3608 & 0.4221 & 0.0586 & 0.1584 & 0.8224 & 8.8825 & 7.3054 & 0.8190 & 7.5127 & 6.1526 \\
\hline$\frac{\Xi}{0}$ & 0.1100 & 0.3496 & 0.4334 & 0.1070 & 0.8254 & 11.5628 & 9.5437 & 0.8220 & 9.6671 & 7.9459 \\
\hline 气ै & 0.2544 & 0.2532 & 0.2524 & 0.2400 & 0.8251 & 11.3417 & 9.3585 & 0.8217 & 9.5086 & 7.8132 \\
\hline T & 0.4883 & 0.1600 & 0.2927 & 0.0590 & 0.8220 & 8.4268 & 6.9265 & 0.8185 & 7.1514 & 5.8782 \\
\hline
\end{tabular}

Table 4 continued

\begin{tabular}{|c|c|c|c|c|c|c|c|c|c|c|}
\hline System & $\mathrm{x}_{1}$ & $\mathrm{x}_{2}$ & $\mathrm{x}_{3}$ & $\mathrm{x}_{4}$ & $\begin{array}{c}\text { Density } \\
\mathrm{kg} / \mathrm{L}\end{array}$ & $\begin{array}{c}\text { Kinematic } \\
\text { Viscosity } \\
\times 10^{6} \\
\left(\mathrm{~m}^{2} / \mathrm{s}\right)\end{array}$ & $\begin{array}{c}\text { Absolute } \\
\text { Viscosity } \\
\text { (mPa.s) }\end{array}$ & $\begin{array}{c}\text { Density } \\
\mathrm{kg} / \mathrm{L}\end{array}$ & $\begin{array}{c}\text { Kinematic } \\
\text { Viscosity } \\
\times 10^{6} \\
\left(\mathrm{~m}^{2} / \mathrm{s}\right)\end{array}$ & $\begin{array}{c}\text { Absolute } \\
\text { Viscosity } \\
\text { (mPa.s) }\end{array}$ \\
\hline & \multicolumn{4}{|c|}{$\mathrm{T}(\mathrm{K})$} & \multicolumn{3}{|c|}{293.15} & \multicolumn{3}{|c|}{298.15} \\
\hline t) & 1.0000 & 0.0000 & 0.0000 & 0.0000 & 0.8035 & 2.8281 & 2.2724 & 0.7996 & 2.4591 & 1.9663 \\
\hline 苂 & 0.0000 & 1.0000 & 0.0000 & 0.0000 & 0.8222 & 8.6400 & 7.1041 & 0.8187 & 7.3198 & 5.9930 \\
\hline 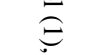 & 0.0000 & 0.0000 & 1.0000 & 0.0000 & 0.8279 & 14.1129 & 11.6834 & 0.8244 & 11.7308 & 9.6713 \\
\hline 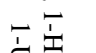 & 0.0000 & 0.0000 & 0.0000 & 1.0000 & 0.8325 & 20.6395 & 17.1818 & 0.8290 & 16.9172 & 14.0250 \\
\hline$\vec{\partial}$ & 0.3023 & 0.2050 & 0.1061 & 0.3865 & 0.8246 & 11.1906 & 9.2277 & 0.8211 & 9.3990 & 7.7178 \\
\hline$\stackrel{0}{0}$ & 0.3879 & 0.1138 & 0.1956 & 0.3027 & 0.8233 & 9.9804 & 8.2170 & 0.8199 & 8.4237 & 6.9062 \\
\hline$\pm \frac{1}{\square}$ & 0.3544 & 0.4372 & 0.0612 & 0.1471 & 0.8206 & 7.8241 & 6.4208 & 0.8171 & 6.6634 & 5.4448 \\
\hline : & 0.1005 & 0.3501 & 0.4397 & 0.1097 & 0.8252 & 11.4077 & 9.4133 & 0.8217 & 9.5427 & 7.8416 \\
\hline$\stackrel{0}{\omega}$ & 0.2542 & 0.2555 & 0.2455 & 0.2449 & 0.8242 & 10.6036 & 8.7397 & 0.8208 & 8.9282 & 7.3279 \\
\hline$\cong$ & 0.4921 & 0.1591 & 0.2933 & 0.0555 & 0.8193 & 7.1141 & 5.8286 & 0.8158 & 6.0804 & 4.9817 \\
\hline
\end{tabular}


Table 4 continued

\begin{tabular}{|c|c|c|c|c|c|c|c|c|c|c|}
\hline \multirow[t]{2}{*}{ System } & $\mathrm{x}_{1}$ & $\mathrm{x}_{2}$ & $x_{3}$ & $\mathrm{x}_{4}$ & $\begin{array}{c}\text { Density } \\
\mathrm{kg} / \mathrm{L}\end{array}$ & $\begin{array}{c}\text { Kinematic } \\
\text { Viscosity } \\
\times 10^{6}\left(\mathrm{~m}^{2} / \mathrm{s}\right)\end{array}$ & $\begin{array}{c}\text { Absolute } \\
\text { Viscosity } \\
\text { (mPa.s) }\end{array}$ & $\begin{array}{c}\text { Density } \\
\mathrm{kg} / \mathrm{L}\end{array}$ & $\begin{array}{c}\text { Kinematic } \\
\text { Viscosity } \\
\times 10^{6}\left(\mathrm{~m}^{2} / \mathrm{s}\right)\end{array}$ & $\begin{array}{l}\text { Absolute } \\
\text { Viscosity } \\
\text { (mPa.s) }\end{array}$ \\
\hline & \multicolumn{4}{|c|}{$\mathrm{T}(\mathrm{K})$} & \multicolumn{3}{|c|}{293.15} & \multicolumn{3}{|c|}{298.15} \\
\hline \multirow{10}{*}{ 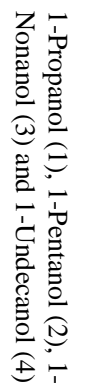 } & 1.0000 & 0.0000 & 0.0000 & 0.0000 & 0.8035 & 2.8281 & 2.2724 & 0.7996 & 2.4591 & 1.9663 \\
\hline & 0.0000 & 1.0000 & 0.0000 & 0.0000 & 0.8146 & 4.9457 & 4.0288 & 0.8110 & 4.3078 & 3.4937 \\
\hline & 0.0000 & 0.0000 & 1.0000 & 0.0000 & 0.8279 & 14.1129 & 11.6834 & 0.8244 & 11.7308 & 9.6713 \\
\hline & 0.0000 & 0.0000 & 0.0000 & 1.0000 & 0.8325 & 20.6395 & 17.1818 & 0.8290 & 16.9172 & 14.0250 \\
\hline & 0.2937 & 0.2050 & 0.1126 & 0.3888 & 0.8236 & 10.3451 & 8.5207 & 0.8202 & 8.6842 & 7.1226 \\
\hline & 0.3925 & 0.1153 & 0.2021 & 0.2901 & 0.8226 & 9.3097 & 7.6582 & 0.8191 & 7.8780 & 6.4530 \\
\hline & 0.3534 & 0.4374 & 0.0612 & 0.1480 & 0.8173 & 6.0898 & 4.9775 & 0.8138 & 5.2347 & 4.2598 \\
\hline & 0.1121 & 0.3454 & 0.3916 & 0.1509 & 0.8236 & 9.7666 & 8.0436 & 0.8201 & 8.2250 & 6.7454 \\
\hline & 0.2570 & 0.2548 & 0.2518 & 0.2364 & 0.8228 & 9.3150 & 7.6643 & 0.8193 & 7.8737 & 6.4510 \\
\hline & 0.4892 & 0.1629 & 0.2934 & 0.0546 & 0.8182 & 6.5646 & 5.3710 & 0.8146 & 5.6712 & 4.6401 \\
\hline
\end{tabular}

Table 4 continued

\begin{tabular}{|c|c|c|c|c|c|c|c|c|c|c|}
\hline \multirow[t]{2}{*}{ System } & $\mathrm{x}_{1}$ & $\mathrm{x}_{2}$ & $\mathrm{x}_{3}$ & $\mathrm{x}_{4}$ & $\begin{array}{c}\text { Density } \\
\mathrm{kg} / \mathrm{L}\end{array}$ & $\begin{array}{c}\text { Kinematic } \\
\text { Viscosity } \\
\times 10^{6} \\
\left(\mathrm{~m}^{2} / \mathrm{s}\right)\end{array}$ & $\begin{array}{c}\text { Absolute } \\
\text { Viscosity } \\
\text { (mPa.s) }\end{array}$ & $\begin{array}{c}\text { Density } \\
\mathrm{kg} / \mathrm{L}\end{array}$ & $\begin{array}{c}\text { Kinematic } \\
\text { Viscosity } \\
\times 10^{6} \\
\left(\mathrm{~m}^{2} / \mathrm{s}\right)\end{array}$ & $\begin{array}{c}\text { Absolute } \\
\text { Viscosity } \\
\text { (mPa.s) }\end{array}$ \\
\hline & \multicolumn{4}{|c|}{$\mathrm{T}(\mathrm{K})$} & \multicolumn{3}{|c|}{293.15} & \multicolumn{3}{|c|}{298.15} \\
\hline \multirow{10}{*}{ 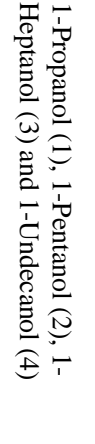 } & 1.0000 & 0.0000 & 0.0000 & 0.0000 & 0.8035 & 2.8281 & 2.2724 & 0.7996 & 2.4591 & 1.9663 \\
\hline & 0.0000 & 1.0000 & 0.0000 & 0.0000 & 0.8146 & 4.9457 & 4.0288 & 0.8110 & 4.3078 & 3.4937 \\
\hline & 0.0000 & 0.0000 & 1.0000 & 0.0000 & 0.8222 & 8.6400 & 7.1041 & 0.8187 & 7.3198 & 5.9930 \\
\hline & 0.0000 & 0.0000 & 0.0000 & 1.0000 & 0.8325 & 20.6395 & 17.1818 & 0.8290 & 16.9172 & 14.0250 \\
\hline & 0.3032 & 0.2067 & 0.1117 & 0.3783 & 0.8226 & 9.4547 & 7.7778 & 0.8192 & 7.9852 & 6.5412 \\
\hline & 0.3898 & 0.1190 & 0.1569 & 0.3344 & 0.8217 & 8.7813 & 7.2157 & 0.8182 & 7.5191 & 6.1522 \\
\hline & 0.3496 & 0.4385 & 0.0627 & 0.1491 & 0.8168 & 5.9895 & 4.8923 & 0.8132 & 5.1797 & 4.2124 \\
\hline & 0.1050 & 0.3559 & 0.4390 & 0.1001 & 0.8201 & 7.4369 & 6.0989 & 0.8166 & 6.3929 & 5.2203 \\
\hline & 0.2462 & 0.2560 & 0.2562 & 0.2416 & 0.8211 & 8.2528 & 6.7767 & 0.8176 & 7.0248 & 5.7437 \\
\hline & 0.4906 & 0.1553 & 0.2968 & 0.0574 & 0.8153 & 5.3890 & 4.3939 & 0.8117 & 4.6802 & 3.8159 \\
\hline
\end{tabular}

Table 5 Density, Kinematic Viscosity, and Calculated Absolute Viscosity of the Quinary System: 1-Propanol, 1-Pentanol, 1-Heptanol, 1Nonanol, and 1-Undecanol

\begin{tabular}{|c|c|c|c|c|c|c|c|c|c|c|c|}
\hline System & $\mathrm{x}_{1}$ & $\mathrm{x}_{2}$ & $\mathrm{x}_{3}$ & $\mathrm{x}_{4}$ & $\mathrm{x}_{5}$ & $\begin{array}{c}\text { Density } \\
\mathrm{kg} / \mathrm{L}\end{array}$ & $\begin{array}{c}\text { Kinematic } \\
\text { Viscosity } \\
\times 10^{6} \\
\left(\mathrm{~m}^{2} / \mathrm{s}\right) \\
\end{array}$ & $\begin{array}{c}\text { Absolute } \\
\text { Viscosity } \\
\text { (mPa.s) }\end{array}$ & $\begin{array}{c}\text { Density } \\
\mathrm{kg} / \mathrm{L}\end{array}$ & $\begin{array}{c}\text { Kinematic } \\
\text { Viscosity } \\
\times 10^{6} \\
\left(\mathrm{~m}^{2} / \mathrm{s}\right) \\
\end{array}$ & $\begin{array}{c}\text { Absolute } \\
\text { Viscosity } \\
\text { (mPa.s) }\end{array}$ \\
\hline & & & $\mathrm{T}(\mathrm{K})$ & & & & 293.15 & & & 298.15 & \\
\hline \multirow{11}{*}{ 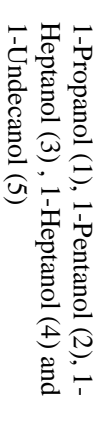 } & 1.0000 & 0.0000 & 0.0000 & 0.0000 & 0.0000 & 0.8035 & 2.8281 & 2.2724 & 0.7996 & 2.4591 & 1.9663 \\
\hline & 0.0000 & 1.0000 & 0.0000 & 0.0000 & 0.0000 & 0.8146 & 4.9457 & 4.0288 & 0.8110 & 4.3078 & 3.4937 \\
\hline & 0.0000 & 0.0000 & 1.0000 & 0.0000 & 0.0000 & 0.8222 & 8.6400 & 7.1041 & 0.8187 & 7.3198 & 5.9930 \\
\hline & 0.0000 & 0.0000 & 0.0000 & 1.0000 & 0.0000 & 0.8279 & 14.1129 & 11.6834 & 0.8244 & 11.7308 & 9.6713 \\
\hline & 0.0000 & 0.0000 & 0.0000 & 0.0000 & 1.0000 & 0.8325 & 20.6395 & 17.1818 & 0.8290 & 16.9172 & 14.0250 \\
\hline & 0.619 & 0.1363 & 0.0809 & 0.119 & 0.0448 & 0.81449 & 5.005 & 4.076 & 0.81073 & 4.356 & 3.531 \\
\hline & 0.3868 & 0.441 & 0.0782 & 0.0283 & 0.0657 & 0.8152 & 5.112 & 4.167 & 0.81149 & 4.453 & 3.613 \\
\hline & 0.2882 & 0.1201 & 0.5074 & 0.0308 & 0.0535 & 0.81922 & 6.789 & 5.562 & 0.81554 & 5.828 & 4.753 \\
\hline & 0.175 & 0.1337 & 0.0855 & 0.5016 & 0.1042 & 0.82436 & 10.33 & 8.517 & 0.82085 & 8.712 & 7.151 \\
\hline & 0.7238 & 0.1361 & 0.0426 & 0.0515 & 0.046 & 0.81151 & 4.169 & 3.383 & 0.80768 & 3.658 & 2.954 \\
\hline & 0.1904 & 0.1575 & 0.1812 & 0.0481 & 0.4228 & 0.82546 & 11.11 & 9.169 & 0.82195 & 9.34 & 7.677 \\
\hline
\end{tabular}


Table 6 Results of Testing Different Models for the Quaternary Systems.

\begin{tabular}{|c|c|c|c|c|c|c|c|c|c|}
\hline \multirow[b]{2}{*}{ System } & \multirow[b]{2}{*}{$\mathrm{T} / \mathrm{K}$} & \multicolumn{2}{|l|}{ Model 1} & \multicolumn{2}{|l|}{ Model 2} & \multicolumn{2}{|l|}{ Model 3} & \multicolumn{2}{|l|}{ Model 4} \\
\hline & & $\% \mathrm{AAD}$ & $\begin{array}{l}\% \\
\text { MAX }\end{array}$ & $\% \mathrm{AAD}$ & $\begin{array}{l}\% \\
\text { MAX }\end{array}$ & $\begin{array}{l}\% \\
\text { AAD }\end{array}$ & $\begin{array}{l}\% \\
\text { MAX }\end{array}$ & $\% \mathrm{AAD}$ & $\begin{array}{l}\% \\
\text { MAX }\end{array}$ \\
\hline $\begin{array}{l}\text { 1-Propanol + 1-Pentanol } \\
+ \text { 1-Heptanol+ 1- }\end{array}$ & 293.15 & 1 & -4.32 & 3.38 & -7.06 & 20.05 & 36.55 & 94.38 & 94.72 \\
\hline Nonanol & 298.15 & 1.31 & -4.89 & 2.65 & -7.03 & 19.23 & 35.70 & 93.71 & 94.13 \\
\hline $\begin{array}{l}\text { 1-Pentanol + 1-Heptanol } \\
\text { + 1-Nonanol+ 1- }\end{array}$ & 293.15 & 0.97 & 2.67 & 1.05 & -3.01 & 6.12 & -19.34 & 94.07 & 94.29 \\
\hline Undecanol & 298.15 & 0.73 & 1.97 & 1.09 & -2.98 & 5.84 & -18.49 & 93.32 & 93.56 \\
\hline $\begin{array}{l}\text { 1-Propanol + 1-Heptanol } \\
\text { + 1-Nonanol + 1- }\end{array}$ & 293.15 & 1.09 & -2.75 & 1.41 & -3.32 & 25.00 & -61.90 & 94.37 & 94.85 \\
\hline Undecanol & 298.15 & 1.09 & 2.67 & 0.94 & -2.23 & 23.74 & -58.84 & 93.66 & 94.21 \\
\hline $\begin{array}{l}\text { 1-Propanol + 1-Pentanol } \\
+1 \text {-Nonanol + 1- }\end{array}$ & 293.15 & 1.09 & -2.78 & 2.08 & -4.11 & 28.14 & -62.07 & 94.42 & 94.9 \\
\hline Undecanol & 298.15 & 1 & 2.71 & 1.45 & -3.47 & 27.20 & -58.48 & 93.72 & 94.32 \\
\hline $\begin{array}{l}\text { 1-Propanol + 1-Pentanol } \\
+1 \text {-Heptanol + 1- }\end{array}$ & 293.15 & 1.22 & 2.71 & 1.28 & -1.83 & 24.56 & -54.99 & 94.43 & 94.91 \\
\hline Undecanol & 298.15 & 1.43 & 3.21 & 0.48 & -0.76 & 23.46 & -52.27 & 93.76 & 94.33 \\
\hline Overall \% AAD & & 1.093 & & 1.581 & & 20.334 & & 93.984 & \\
\hline
\end{tabular}

Table 7 Results of Testing Different Models for the Quinary System

\begin{tabular}{|c|c|c|c|c|c|c|c|c|c|}
\hline \multirow{5}{*}{ System } & & \multicolumn{2}{|l|}{ Model 1} & \multicolumn{2}{|l|}{ Model 2} & \multicolumn{2}{|l|}{ Model 3} & \multicolumn{2}{|l|}{ Model 4} \\
\hline & & $\%$ & $\%$ & $\%$ & & $\%$ AAD & $\%$ & & $\%$ \\
\hline & $\mathrm{T} / \mathrm{K}$ & $\mathrm{AAD}$ & MAX & $\mathrm{AAD}$ & $\%$ MAX & & MAX & AAD & MAX \\
\hline & 293. & & & & & & & & \\
\hline & 15 & 3.94 & 10.25 & 1.65 & 4.39 & 19.83 & 55 & 30.61 & 62.65 \\
\hline 1-Propanol + 1-Pentanol + 1- & 298. & & & & & & & & \\
\hline Heptanol+1-Nonanol + 1-Undecanol & 15 & 4.25 & 10.05 & 1.20 & 3.43 & 20.17 & 54 & 26.99 & 59.03 \\
\hline Overall \% AAD & & 4.10 & & 1.43 & & 20 & & 28.80 & \\
\hline
\end{tabular}

\section{Conclusions}

The kinematic viscosities and densities of five quaternary and one quinary system of 1-propanol, 1-pentanol, 1-heptanol, 1-nonanol, and 1-undecanol over the entire composition range were measured at 293.15 and $298.15 \mathrm{~K}$. The measured kinematic viscosity values reported in this work were compared to the calculated values of kinematic viscosity of the four selected viscosity models. The predictive capability of each of the viscosity models was determined by calculating the percent average absolute deviation (\%AAD). For the investigated systems the generalized McAllister model and the GC-UNIMOD model showed the best overall predictive capability of all models with a \% AAD value of 1.093 for quaternary and $1.43 \%$ for quinary system respectively.

\section{Acknowledgement}

The authors acknowledge with thanks a discovery grant from the Natural Sciences and Engineering Council of Canada (NSERC).

\section{Nomenclature}

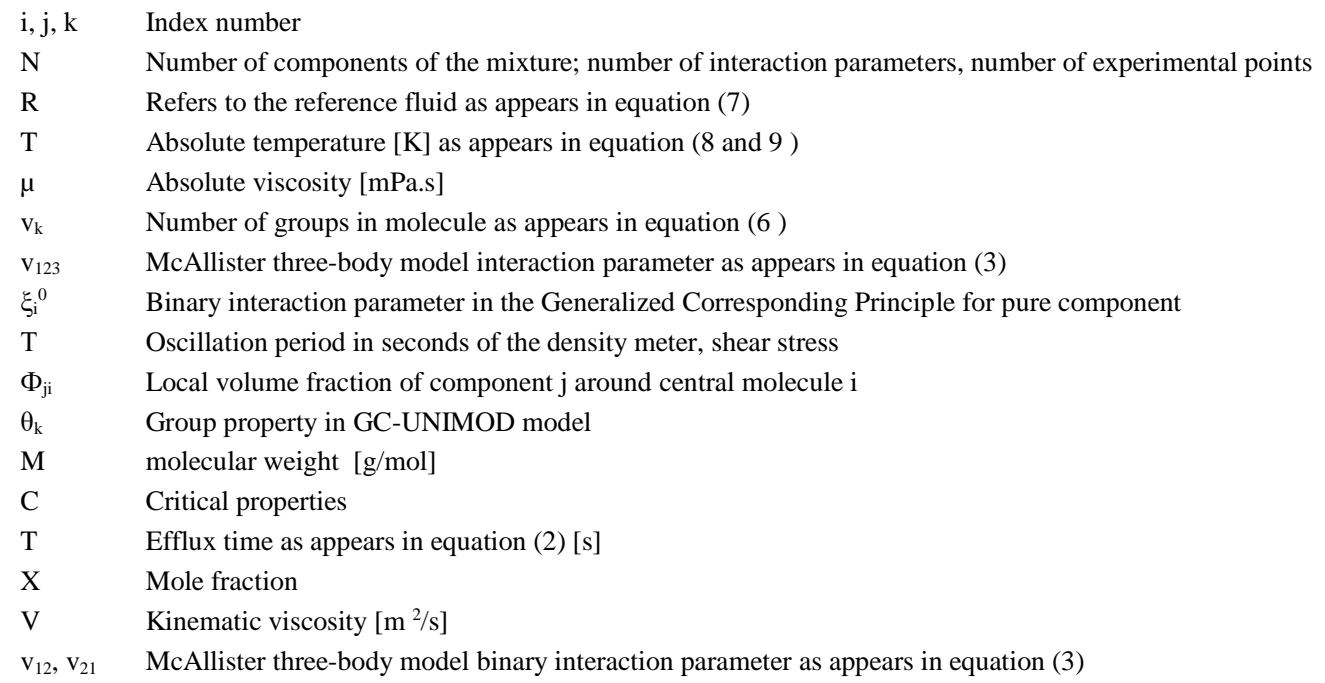


$\xi_{\mathrm{ij}} \quad$ Binary interaction parameter in the Generalized Corresponding Principle

$\rho \quad$ Density $\left[\mathrm{kg} / \mathrm{m}^{3}\right]$

$\Phi \quad$ Shape factor, volume fraction

$\Omega \quad$ Acentric factor

\section{References}

Al-Jimaz, A. S., Al-Kandary, J. A., and A. M. Abdul-latif, "Densities and Viscosities for Binary Mixtures of Phenetole with 1-Pentanol, 1-Hexanol, 1-Heptanol, 1-Octanol, 1-Nonanol, and 1-Decanol at Different Temperatures", Fluid Phase Equilibria, 218, 247-260 (2004).

Al-Hayan, M.N.M., and A. M. Abdul-latif, "Excess Molar Volumes and Viscosities of (1,1,2,2-Tetrabromoethane+1-Alkanols $)$ at T = (293.15 and 303.15 K)". J. Chem. Thermodynamics., 38, 68-74 (2006).

Allan, J.M.; and A. S. Teja, "Correlation and Prediction of Viscosity of Defined and Undefined Hydrocarbon Liquids", Can. J. Chem. Eng,. 69, 986-991 (1991).

Asfour, A., Mutual and Intra-(self-) diffusion coefficients and viscosities of binary liquid solutions at $25.00^{\circ} \mathrm{C}$. Ph.D. Thesis, University of Waterloo, Waterloo, Canada, 1980.

Cao, W.; Knudsen, K.; Fredenslund, A.; and P., Rasmussen, "Group-Contribution Viscosity Predictions of Liquid Mixtures Using UNIFAC-VLE Parameters", Ind. Eng. Chem. Res., 32, 2088-2092 (1993).

Faria, Marco A. Francüa; de Sa', Camila F.; Lima, Glauber R.; Filho, Joaquim I. B. C.; Martins, Rosana J.; Cardoso; Ma’ rcio J. E. de M.; Barcia, and E. Oswaldo, "Measurement of Density and Viscosity of Binary 1-Alkanol Systems $\left(\mathrm{C}_{8}-\mathrm{C}_{11}\right)$ at $101 \mathrm{kPa}$ and Temperatures from 283.15 to $313.15 \mathrm{~K}$ ", . J. Chem. Eng. Data., 50, 1938-1943 (2005).

Gowrisankara M.; Venkateswarluc P.; Siva kumard K. and S. Sivarambabu, "Density, Ultrasonic Velocity, Viscosity and Their Excess Parameters of the Binary Mixtures of N,N- Diethyl Aniline with 1-Alkanols (C3-C5), + 2-Alkanols (C3-C4) at 303.15 K", International Journal of Scientific \& Engineering Research, 4, $1008-1027$ (2013)

Handali, A. and S. Kianersi, "Measurement of Volumetric and Viscometric Properties of Binary Mixtures of Methyl Tert-butyl Ether (MTBE) + 1-Alcohol from

Hussein, N., "A Study of the Viscometric and Volumetric Properties of 1-Alkanol (C3 - C11) Multi-component Liquid Systems at Different Temperature Levels". M.A.Sc. Thesis, University of Windsor. Windsor, Canada, 2007.

Nhaesi, A. H., and A. A. Asfour, "Prediction of the Viscosity of Multicomponent Liquid Mixtures: A generalized McAllister Three-body Interaction Model", Chem. Eng. Sci., 55, 2861-2873 (2000)

Reid, R. C.; Praunitz, J.M.; and T.K. Shenvood, "The Properties of Gases and Liquids," McGeaw-Hill, New York, (1987).

Shalmashi, A.; and F. Amani, "Densities and Excess Molar Volumes for Binary Solution of Water + Ethanol + Methanol and Propanol From (283.15 to 313.15) K. Latin American Applied Research. 2014, 44, 163-166.

Shan, Z., "An Experimental Study of the Viscometric and Volumetric Properties of 1-Alkanol Multi-Component Liquid Mixtures at Several Temperature Level". Ph.D. Thesis, University of Windsor. Windsor, Canada, 2000.

Teja, A. S., and P. Rice, "Generalized Corresponding States Method For the Viscosities of Liquid Mixtures", I\&EC Fundam., 20, 77-81 (19981).

TRC Thermodynamic Tables - Hydrocarbons; Thermodynamic Research Center, Texas A\&M University: College Station, TX, 1988.

Wong, D. S. H.; Sandler, S. I.; and A.S. Teja, "Vapor-Liquid Equilibrium Calculations by Use of Generalized Corresponding States Principle. I. New Mixing Rules g" I\&EC Fundam, 23, 38-44 (1994) 